\title{
Association of Different Transcranial Doppler- derived Indices of Cerebrovascular Dynamics With Delayed Cerebral Ischemia in Patients Suffering From Subarachnoid Hemorrhage: A Retrospective Study
}

Vasilios Papaioannou ( $\nabla$ vapapa@med.duth.gr)

Democritus University of Thrace Department of Medicine https://orcid.org/0000-0002-2637-0160

Karol Budohoski

Cambridge University Hospitals NHS Foundation Trust

Michal Placek

Cambridge University: University of Cambridge

\section{Zofia Czosnyka}

Cambridge University: University of Cambridge

\section{Peter Smielewski}

Cambridge University: University of Cambridge

Marek Czosnyka

Cambridge University: University of Cambridge

\section{Research}

Keywords: Cerebral blood flow, delayed cerebral ischemia, subarachnoid hemorrhage, slow waves, time constant, transcranial doppler, vasospasm

Posted Date: November 12th, 2020

DOl: https://doi.org/10.21203/rs.3.rs-103535/v1

License: (c) (1) This work is licensed under a Creative Commons Attribution 4.0 International License. Read Full License

Version of Record: A version of this preprint was published on March 26th, 2021. See the published version at https://doi.org/10.1186/s40635-021-00378-8. 


\section{Abstract}

\section{Background}

Cerebral vasospasm (VS) and delayed cerebral ischemia (DCl) constitute major complications following subarachnoid hemorrhage (SAH). A few studies have examined the relationship between different indices of cerebrovascular dynamics with the occurrence of VS. However, their potential association with the development of $\mathrm{DCl}$ remains elusive. In this study, we investigated the pattern of changes of different transcranial doppler-derived indices of cerebrovascular dynamics during vasospasm in patients suffering from subarachnoid hemorrhage, dichotomized by the presence of delayed cerebral ischemia.

Methods

A retrospective analysis was performed using recordings from $32 \mathrm{SAH}$ patients, diagnosed with VS. Patients were divided in 2 groups, depending on development of DCl. Magnitude of slow waves (SWs) of cerebral blood flow velocity (CBFV) and arterial blood pressure was measured.

Cerebral autoregulation was estimated using the moving correlation coefficient Mxa. Cerebral arterial time constant (tau) was expressed as the product of resistance and compliance.

Results

In the whole population ( $\mathrm{N}=32$ ), magnitude of SWs of ipsilateral CBFV was increased during vasospasm $(4.15 \pm 1.55$ vs before: $2.86 \pm 1.21 \mathrm{~cm} / \mathrm{sec}, \mathrm{p}<0.001)$. Ipsilateral SWs of CBFV before VS had higher magnitude in $\mathrm{DCl}$ group $(\mathrm{p}<0.001)$ and were strongly predictive of $\mathrm{DCl}$, with area under the curve $=0.745$, $p=0.009$. VS caused shortening of tau (ipsilateral to spasm: $0.17 \pm 0.08$ vs before: $0.25 \pm 0.17 \mathrm{sec}, p=$ $0.04)$ and interhemispheric asymmetry with lower values on ipsilateral side $(p<0.01)$. In patients with $\mathrm{DCl}$ $(\mathrm{N}=19), \mathrm{Mxa}$ was increased during VS (ipsilateral to spasm: $0.36 \pm 0.18$ vs before: $0.26 \pm 0.23, p=0.04$ ).

\section{Conclusions}

In the whole group of patients, VS was associated with increased CBFV SWs in both temporal and spatial assessments. Greater SWs before VS in DCl group, were strongly predictive of $\mathrm{DCl}$.

\section{Background}

Cerebral vasospasm (VS) and delayed cerebral ischemia ( $\mathrm{DCl}$ ) constitute major complications following subarachnoid hemorrhage (SAH). DCl has been shown to occur in approximately $40 \%$ of patients suffering from SAH. It is more common in those who develop VS in large cerebral arteries, since arterial narrowing has a delayed onset with a peak between 5- and 14-days post ictus [1]. However, the maximum rate of $\mathrm{DCl}$ in patients with VS is around $50 \%$, whereas up to one-third of patients with $\mathrm{DCl}$ do not exhibit large artery vasospasm $[1,2]$. In this respect, different studies have found that a combination of VS and dysfunction of cerebral autoregulation during the first 4-5 days post-SAH correlate with the occurrence of 
DCl [3-5]. Such scenario is in accordance with Harper's dual-insult theory, which states that two hemodynamic insults, such as vascular spasm and autoregulatory failure, are needed to induce ischemia [6]. Nevertheless, such theory cannot explain why hypoperfusion can also be observed in areas not supplied by spastic arteries [7].

Different experimental studies have found that during the acute phase of SAH, global cerebral ischemia, blood-brain barrier disruption, cortical spreading depolarizations, microvascular spasm with endothelial dysfunction, as well as activation of an inflammatory cascade might contribute to increased tissue vulnerability to secondary insults $[1,2,8]$. It is unclear whether disturbed autoregulation is a consequence of such pathophysiological mechanisms. However, as has been suggested [7], loss of autoregulation is an ongoing and dynamic process with occasionally different mechanisms of origin. Thus, macrovascular spasm leads to distal compensatory vasodilatation with shortening of autoregulatory plateau which could signal impaired autoregulation upon testing, whereas microvascular spasm might induce a shift of the plateau to the right, towards higher arterial blood pressure (ABP) [7].

Surrogate markers of cerebral blood flow (CBF), such as transcranial doppler (TCD) cerebral blood flow velocity (CBFV), are frequently used to monitor development of VS, as well as integrity of autoregulation, through estimation of the dynamic changes that take place between $A B P$ and $C B F V$ in a frequency range of 'slow waves' (0.005 to $0.05 \mathrm{~Hz}$ ) [9]. In this respect, different physiological parameters can be estimated, such as the index Mx evaluating the low frequency autoregulatory response [10], or other 'high frequency' components of autoregulation, like cerebrovascular time constant (tau), being a product of resistance (CVR) and compliance (Ca) [11-14]. Furthermore, other secondary indices describing cerebrovascular dynamics have been introduced, such as CBFV slow waves (SWs), which reflect dynamic oscillations in cerebral blood volume related to autoregulatory vasodilatation and vasoconstriction [15]. Finally, complexity analysis of TCD-derived CBFV signals has been applied for assessing a possible 'decomplexification' of cerebral circulation during different pathologic states $[16,17]$.

The clinical significance of such indices has been tested in patients suffering from $\mathrm{SAH}$, where shortening of tau [18] and both reduced [16] and gradually increasing complexity of CBFV [17], have been found in different studies, during VS. However, their potential relationship with the occurrence of $\mathrm{DCl}$ has not been evaluated yet. A few studies so far, have shown a significant association between unilateral autoregulatory failure and development of $\mathrm{DCl}$ [3-5]. In addition, the nature of SWs remains elusive since they have been observed in both healthy and pathologic states [15]. However, their absence has been associated with worse outcome in patients with traumatic brain injury (TBI) [15-19].

The primary aim of this study was to assess for the first time, how VS affects different TCD-derived parameters that describe both low- and high frequency components of cerebral autoregulation in patients after SAH, admitted to the Neurosciences and Trauma Critical Care Unit (NCCU), Department of Neurosurgery at Addenbrooke's Hospital, Cambridge, UK, with a special attention put into slow waves of blood flow velocity. SWs of both ABP and CBFV were measured in order to estimate the potential impact of VS upon their magnitude, as well as their relative changes. Secondly, we explored the potential 
differences of VS-associated changes in cerebrovascular dynamics between subgroups of patients with and without $\mathrm{DCl}$, in both temporal and spatial settings. Finally, we explored if there is any prognostic value of TCD-derived parameters related to the occurrence of $\mathrm{DCl}$.

\section{Methods}

Study population

We retrospectively analyzed digitally recorded and prospectively collected data from patients admitted to the NCCU, Department of Neurosurgery at Addenbrooke's Hospital between June 2010 and January 2012 with a diagnosis of SAH, examined with TCD to assess state of autoregulation and detect VS $[4,5]$. Written consent and approval of the study was given by both patients and the local Addenbrooke's Research Ethics Committee, respectively.

Aneurysmal SAH was confirmed with either computed tomography (CT) or digital subtraction angiography (DSA). Out of 98 patients after SAH included in original studies [4,5], 32 conscious patients (mean age: $52.4 \pm 10,12$ males and 20 females) who developed TCD-detected VS were included in our study. Study design is presented in Figure 1. Vasospasm was defined as mean blood flow velocity in the middle cerebral artery (CBFV $\mathrm{MCA}_{\mathrm{A}}$ ) higher than $120 \mathrm{~cm} / \mathrm{sec}$ and Lindegaard ratio (LR), which is the ratio between blood flow velocity of MCA and internal carotid artery (ICA), higher than $3[20,21]$. Median onset of VS was 6 days after SAH. Nineteen patients developed DCI within 21 days of ictus. DCl was defined as a drop of $\geq 2$ points on the Glasgow coma scale (GCS) lasting more than 2 hours, after excluding intracranial hemorrhage, acute hydrocephalus, seizures, metabolic derangements or infection, with or without radiological signs of cerebral VS, as has been previously described $[4,5,22]$. Confirmation of DCI was made through imaging in unconscious patients $[4,5]$.

All patients were treated with oral nimodipine $60 \mathrm{mg}$ every $4 \mathrm{~h}$, whereas those we developed $\mathrm{DCl}$ received hypertensive, hypervolemic and hemodilutional therapy [23]. Neurologic status upon admission was assessed using GCS and the World Federation of Neurosurgical Societies (WFNS) scale, whereas modified Fisher scale was used for grading the amount of subarachnoid blood [24]. The Glasgow Outcome Scale (GOS) was used for assessing outcome at discharge from hospital.

Monitoring and data analysis

Arterial blood pressure was monitored non-invasively with Finapres 2300 (Ohmeda, Amsterdam, the Netherlands) via a finger cuff, with the hand kept at the heart level in all patients. Patients were supine with the head of the bed raised $30^{\circ}$ to $45^{\circ}$. In one patient $A B P$ was monitored invasively from the radial arterial artery using a pressure monitoring kit (Baxter HealthCare, $\mathrm{CA}$ ).

Bilateral TCD examinations of extracranial internal carotid arteries and MCA were performed, using $2 \mathrm{MHz}$ probes with Doppler Box (DWL Compumedics Germany). The raw data signals were recorded at sampling frequency of $100 \mathrm{~Hz}$ using ICM+ software (Cambridge Enterprise, Cambridge, UK, 
https://icmplus.neurosurg.cam.ac. uk/). Mean values of signals were calculated averaging their values in a 10-second time window and then secondly averaging over the whole monitoring period (30-40 minutes). Only sessions with minimum of 30 minutes of simultaneous $A B P$ and bilateral $C B F V_{M C A}$ recordings were included in the analyses.

Average measurements from 3 days of TCD recordings before and during VS, as well as differences between ipsilateral and contralateral to the VS sides were compared for all patients and between subgroups with and without $\mathrm{DCl}$. Both location of VS on TCD and lateralization of ischemic symptoms were used for assessing hemispheric differences of various measured cerebrovascular properties. When bilateral VS was present, the analysis included averaging of both sides.

Calculation of different cerebrovascular parameters

Slow waves (SWs)

The magnitude of slow waves was assessed using spectral analysis of $\mathrm{CBFV}_{\mathrm{MCA}}$ and $\mathrm{ABP}$ waveforms and calculated as the square root of the power of the signal in the frequency range between 0.05 and $0.005 \mathrm{~Hz}$ [14], using ICM+ software. Artefacts were manually removed prior to analysis.

Cerebral arterial time constant (tau)

The time constant of cerebral arterial bed is a TCD-derived index indicating how fast 'arterial blood stabilizes after a change in $A B P^{\prime}[14,18]$. In other words, it can reflect 'the time of the filling arterial bed distal to the level of insonated vessel, following cardiac systole'[14]. In that case, although CBFV $_{M C A}$ is measured within a large artery, tau describes the distal vascular network as the product of Ca and CVRa:

tau $=\mathrm{Ca} * \mathrm{CVRa}=$

$\left(\mathrm{AMP}_{\mathrm{CaBV}}{ }^{\star} \mathrm{Sa} / \mathrm{AMP}_{\mathrm{ABP}}\right) *\left[\right.$ mean $\mathrm{ABP} /\left(\right.$ mean $\mathrm{CBFV}_{\mathrm{MCA}}$ * $\left.\left.\mathrm{Sa}\right)\right][$ sec] equation 1

where $\mathrm{Sa}$ is the cross-sectional area of the insonated vessel that can be ultimately omitted from the equation, CVRa is the resistance of small cerebral arteries and arterioles estimated using ABP instead of cerebral perfusion pressure, $\mathrm{AMP}_{\mathrm{CaBV}}$ and $\mathrm{AMP}_{\mathrm{ABP}}$ are the fundamental harmonic amplitudes of the pulse changes of cerebral arterial blood volume (CaBV) and ABP respectively, calculated using Fast Fourier transformation of their original time series. Pulsatile changes of cerebral arterial blood volume $(\triangle \mathrm{CaBV})$ can be estimated using the methodology first described by Avezaat and van Eijnhoven [25], where $\Delta \mathrm{CaBV}$ during a cardiac cycle is calculated as an integral of the difference between arterial pulsatile inflow and venous outflow of cerebral blood [12,13]. Tau enables comparisons between different patients and allows for assessing whether alterations in compliance are balanced by changes in resistance and vice versa $[12,14]$.

Mean velocity autoregulation index (Mxa) 
The TCD-derived mean velocity index $(\mathrm{Mx})$ can be measured for assessing cerebral autoregulation. It is calculated as a Pearson's moving correlation coefficient between 30 consecutive samples of averaged (over 10 seconds) cerebral perfusion pressure (CPP) and mean $\mathrm{CBFV}_{\mathrm{MCA}}$ with an update every 10 seconds [10]. In this study, ABP instead of CPP was measured, giving rise to the Mxa index. A passive transmission of $A B P$ fluctuations to mean flow velocity reflects impaired cerebral autoregulation and therefore, the calculated Mxa will be positive. A zero or negative Mxa signifies none or inverse association between $A B P$ and $C B F V_{M C A}$, something that is associated with preserved autoregulation [10]. In patients suffering from SAH, it has been suggested that values of Mxa during VS greater than 0.46 indicate impaired autoregulation [26].

\section{Sample entropy (SampEn)}

We applied SampEn as a measure of complexity of physiological time series [27]. Sample entropy represents the negative natural logarithm of the conditional probability that two sequences similar for $\mathrm{m}$ points remain similar at the next point $(m+1)$ with a tolerance $r$. The parameter $r$ that is the tolerance for accepting matches, is usually set between $15-25 \%$ of standard deviation (SD) of the time series after normalization ( $S D=1)$. The parameter $\mathrm{m}$ (embedding dimension) is the length of sequences to be compared and its values is usually set to 1 or 2 for data length ranging from 100 to 5000 data points. In our analysis, we computed SampEn of $\mathrm{CBFV}_{\mathrm{MCA}}$ signals, using ICM+ software assigning the values of 2 for $m$ and 0.15 for $r$.

Statistical analysis

Statistical analysis was performed using IBM SPSS Statistics 26 package (Armonk, NY, USA). Patients were dichotomized into $\mathrm{DCl}$ and non-DCl groups. The assumption of normal distribution was confirmed using Kolmogorov-Smirnoff test. The $x^{2}$ test was used for categorial variables. Temporal comparisons between TCD-derived indices before (pre-VS) and during VS, as well as spatial comparisons between ipsilateral and contralateral sides were performed using t-paired test for the overall group of patients. The t-test for independent samples was used for comparisons between groups with and without $\mathrm{DCl}$. Values were averaged per monitoring session, before and during VS, based on the TCD onset of VS for each patient. Bivariate correlations between different measured variables were estimated using the Pearson $r$ coefficient. Binary logistic regression and Receiver Operating Characteristic (ROC) curve analysis were applied for analyzing the potential association between measured parameters with development of DCl. Data are presented as mean $\pm S D$, whereas the level of significance ( $p$ value) was set at 0.05 .

\section{Results}

Table 1 summarizes the baseline characteristics for the included patients divided by the presence of DCl. The two cohorts did not differ in terms of age, WFNS and modified Fisher scales, GCS upon both admission and discharge, as well as GOS. ABP values did not differ significantly between pre VS and VS period of measurements, neither for the whole population nor between and within groups. 
Ipsilateral mean CBFV values were significantly increased during VS in all patients (spasm: $156.2 \pm 23.7$ vs before: $89.6 \pm 22.5 \mathrm{~cm} / \mathrm{sec}, \mathrm{p}<0.001$ ), as well as in both groups with and without DCl (spasm: $150.8 \pm$ 33.2 vs before: $90.9 \pm 25.5 \mathrm{~cm} / \mathrm{sec}, \mathrm{p}<0.001$ for $\mathrm{DCl} \& 167.9 \pm 33.7$ vs $85.9 \pm 22.4 \mathrm{~cm} / \mathrm{sec}, \mathrm{p}<0.001$ for non $\mathrm{DCl}$ group, respectively). However, they did not differ between groups significantly, neither before nor during spasm.

Differences of measured TCD-derived variables before and during VS for all patients, are presented in Table 2, whereas differences between groups with and without $\mathrm{DCl}$ are shown in Table 3 .

Table 1. Characteristics of all patients and subgroups with and without DCl. 


\begin{tabular}{|c|c|c|c|c|}
\hline Variables & $\begin{array}{l}\text { Overall } \\
(\mathrm{N}=32)\end{array}$ & $\begin{array}{l}\mathrm{DCl} \\
(\mathrm{N}=19)\end{array}$ & $\begin{array}{l}\text { Non-DCl } \\
(\mathrm{N}=13)\end{array}$ & $\mathrm{p}$ value \\
\hline Age, years \pm SD & $52.4 \pm 10$ & $54.15 \pm 11.8$ & $50 \pm 7.6$ & $0.27^{\$}$ \\
\hline Sex (male/female) & $12 / 20$ & $8 / 11$ & $4 / 9$ & $0.74^{\#}$ \\
\hline $\begin{array}{l}\text { WFNS (mean) } \\
\text { Modified Fisher scale }\end{array}$ & $2.37 \pm 1.33$ & $2.36 \pm 1.38$ & $2.38 \pm 1.32$ & $0.97^{\#}$ \\
\hline GCS admission & $3 \pm 0.8$ & $3.2 \pm 0.7$ & $3.1 \pm 1$ & \multirow{2}{*}{$0.94^{\#}$} \\
\hline GCS discharge & $12.2 \pm 3.4$ & $12.4 \pm 3.2$ & $11.9 \pm 3.8$ & \\
\hline GOS & $13.8 \pm 2.9$ & $13.2 \pm 3$ & $14.1 \pm 1$ & $0.70^{\#}$ \\
\hline Aneurysm location & $4 \pm 1$ & $4 \pm 1$ & $4 \pm 1$ & $0.16^{\#}$ \\
\hline 1. AcomA & & & & \multirow[t]{2}{*}{$0.55^{\#}$} \\
\hline 2. $M C A$ & & & & \\
\hline 3. PcomA & 9 & 6 & 3 & \multirow[b]{2}{*}{$0.53^{\#}$} \\
\hline 4. PICA & 8 & 4 & 4 & \\
\hline 5. $B A$ & 9 & 6 & 3 & \multirow{2}{*}{$0.93^{\#}$} \\
\hline 6. ICA & 4 & 2 & 2 & \\
\hline VS side & 1 & 0 & 1 & $0.12^{\#}$ \\
\hline 1. Right & 1 & 1 & 0 & $0.46^{\#}$ \\
\hline 2. Left & & & & $0.35^{\#}$ \\
\hline 3. Bilateral & 14 & 9 & 5 & \multirow[t]{2}{*}{$0.32^{\#}$} \\
\hline Clipping/coiling & 11 & 6 & 5 & \\
\hline \multirow[t]{5}{*}{ Rebleeding } & 7 & 4 & 3 & $0.44^{\#}$ \\
\hline & $20 / 12$ & $12 / 7$ & $8 / 5$ & $0.67^{\#}$ \\
\hline & 1 & 0 & 1 & $0.72^{\#}$ \\
\hline & & & & $0.40^{\#}$ \\
\hline & & & & $0.32^{\#}$ \\
\hline
\end{tabular}

DCI: delayed cerebral ischemia, WFNS: World Federation of Neurosurgical Societies, GCS: Glasgow Coma Scale, GOS: Glasgow outcome scale, AcomA: anterior com-municating artery, MCA: middle cerebral artery, 
PcomA: posterior communicating artery, PICA: posterior inferior cerebellar artery, BA: basilar artery, ICA: internal carotid artery, VS: vasospasm, SD: standard deviation, ${ }^{\$}$ :2-tailed t-test, ${ }^{\#}: x^{2}$ test.

Table 2. Temporal (pre VS vs VS) and spatial (ipsilateral vs contralateral) differences of mean values of different measured parameters across the overall study population $(\mathrm{N}=32$, paired samples t-test).

\begin{tabular}{|lllll|}
\hline Variables & Side of measurement & Pre VS & During VS & p value \\
& & & & \\
\hline CBFV SWs & ipsilateral & $2.86 \pm 1.21$ & $4.15 \pm 1.55$ & $<0.001$ \\
[cm/sec] & contralateral & $2.89 \pm 1.48$ & $3.29 \pm 1.3$ & 0.73 \\
& p value & 0.92 & 0.01 & \\
Tau & ipsilateral & $0.25 \pm 0.17$ & $0.17 \pm 0.08$ & 0.04 \\
[sec] & contralateral & $0.28 \pm 0.16$ & $0.19 \pm 0.09$ & 0.50 \\
& p value & 0.32 & 0.01 & \\
Mxa & ipsilateral & $0.24 \pm 0.20$ & $0.31 \pm 0.21$ & 0.16 \\
& contralateral & $0.20 \pm 0.18$ & $0.23 \pm 0.26$ & 0.15 \\
& p value & 0.55 & 0.23 & \\
SampEn & ipsilateral & $2.67 \pm 0.93$ & $3.00 \pm 0.96$ & 0.15 \\
& contralateral & $2.95 \pm 1.32$ & $3.16 \pm 2.15$ & 0.15 \\
& p value & 0.63 & 0.70 & \\
\hline
\end{tabular}

VS: vasospasm, Tau: time constant, CBFV SWs: cerebral blood flow velocity slow waves, Mxa: mean autoregulatory velocity index, SampEn: sample entropy.

Table 3. Temporal (pre VS vs VS) and spatial (ipsilateral vs contralateral) differences of mean values of different parameters between $\mathrm{DCl}$ and non- $\mathrm{DCl}$ groups of patients (t-test for independent samples). 


\begin{tabular}{|c|c|c|c|c|}
\hline \multicolumn{5}{|c|}{ Spatial comparisons during VS (ipsilateral vs contralateral) } \\
\hline \multirow[b]{2}{*}{ Variables } & Side of measurement & $\mathrm{DCl}$ & Non-DCl & $\mathrm{p}$ value \\
\hline & & $(N=19)$ & $(\mathrm{N}=13)$ & \\
\hline \multirow[t]{3}{*}{ Mxa } & ipsilateral & $0.36 \pm 0.18$ & $0.26 \pm 0.23$ & 0.04 \\
\hline & contralateral & $0.21 \pm 0.23$ & $0.23 \pm 0.32$ & 0.52 \\
\hline & $\mathrm{p}$ value & 0.03 & 0.62 & \\
\hline \multicolumn{5}{|c|}{ Temporal comparisons (ipsilateral pre VS vs during VS) } \\
\hline \multirow{2}{*}{\multicolumn{2}{|c|}{ Variables }} & $\mathrm{DCl}$ & \multirow{2}{*}{\multicolumn{2}{|c|}{$\begin{array}{l}\text { Non-DCl p value } \\
(\mathrm{N}=13)\end{array}$}} \\
\hline & & $(\mathrm{N}=19)$ & & \\
\hline CBFV SWs & pre VS & $3.20 \pm 1.02$ & $2.25 \pm 1.08$ & $<0.001$ \\
\hline \multirow[t]{2}{*}[\mathrm{cm}/\mathrm{sec}]{} & during VS & $3.95 \pm 1.45$ & $4.64 \pm 1.43$ & 0.31 \\
\hline & $p$ value & 0.62 & $<0.001$ & \\
\hline \multirow[t]{3}{*}{ Mxa } & pre VS & $0.23 \pm 0.23$ & $0.26 \pm 0.16$ & 0.52 \\
\hline & during VS & $0.36 \pm 0.18$ & $0.26 \pm 0.23$ & 0.04 \\
\hline & $\mathrm{p}$ value & 0.04 & 0.32 & \\
\hline \multirow[t]{3}{*}{ tau (sec) } & pre VS & $0.31 \pm 0.20$ & $0.20 \pm 0.09$ & 0.42 \\
\hline & during VS & $0.18 \pm 0.09$ & $0.17 \pm 0.10$ & 0.53 \\
\hline & $\mathrm{p}$ value & 0.06 & 0.4 & \\
\hline \multirow[t]{3}{*}{ SampEn } & pre VS & $2.6 \pm 0.9$ & $2.7 \pm 0.9$ & 0.8 \\
\hline & during VS & $3.03 \pm 1.01$ & $2.9 \pm 0.9$ & 0.62 \\
\hline & $p$ value & $p=0.2$ & $p=0.8$ & \\
\hline
\end{tabular}

VS: vasospasm, DCl: delayed cerebral ischemia, tau: time constant, CBFV SWs: cerebral blood flow velocity slow waves, Mxa: mean autoregulatory velocity index, SampEn: sample entropy.

Slow waves of CBFV and $\mathrm{ABP}$

During VS, magnitude of SWs of CBFV was significantly increased related to pre VS measurements on the ipsilateral side $(4.15 \pm 1.55$ vs $2.86 \pm 1.21 \mathrm{~cm} / \mathrm{sec}, \mathrm{p}<0.001,95 \% \mathrm{Cl}: 0.72-2)$ for the whole studying population. Similar differences were found during spatial assessments (Table 2).

Ipsilateral CBFV SWs exhibited significant increase during VS in the non-DCl group compared to pre VS values (4.64 \pm 1.43 vs $2.25 \pm 1.08 \mathrm{~cm} / \mathrm{sec}, \mathrm{p}<0.001,95 \% \mathrm{Cl}: 1.55-3.22$, Table 3 , Figure 2). Moreover, 
patients with $\mathrm{DCl}$ had significantly increased ipsilateral SWs before VS in relation with non-DCl group ( $3.20 \pm 1.02$ vs $2.25 \pm 1.08 \mathrm{~cm} / \mathrm{sec}, \mathrm{p}<0.001,95 \%$ Cl: $0.23-1.82)$.

On the contrary, SWs of ABP did not exhibit significant differences during VS, neither for the whole patients' population (before: $2.19 \pm 1.42$ vs spasm: $2.42 \pm 1.26 \mathrm{mmHg}, \mathrm{p}=0.29$ ), nor within groups (before: $2.48 \pm 1.31$ vs spasm: $2.32 \pm 0.81 \mathrm{mmHg}, p=0.62$ for $\mathrm{DCl} \& 1.93 \pm 1.52$ vs $2.32 \pm 1.72 \mathrm{mmHg}, p$ $=0.16$ for non-DCl group, respectively). Finally, no differences between groups were found as well.

Tau, Mxa and SampEn

Ipsilateral tau during VS was significantly shortened in relation to pre VS period of measurements $(\mathrm{p}=$ $0.04,95 \% \mathrm{Cl}:-0.003$ to -0.16$)$, as well as compared to contralateral side ( $p=0.01,95 \% \mathrm{Cl}:-0.004$ to -0.35 , Table 2). Nevertheless, when stratified by $D C l$, the ipsilateral difference did not reach significance $(p=$ 0.06 for $\mathrm{DCl}$ group and $\mathrm{p}=0.4$ for non-DCl group, respectively, Table 3 ), whereas no differences were found between cohorts during both pre VS and VS periods of recordings.

Ipsilateral Mxa was greater during VS compared to pre VS values but differences were not statistically significant ( $p=0.16$, Table 2). On the contrary, when stratified by DCl, the ipsilateral Mxa was significantly increased during VS in DCl vs non-DCl groups of patients ( $p=0.04,95 \% \mathrm{Cl}: 0.03-0.23$, Table 3 ). Furthermore, in pairwise comparisons, Mxa was significantly higher in both temporal and spatial assessments in the $\mathrm{DCl}$ cohort (Table 3).

Ipsilateral SampEn was greater during VS compared to pre VS values but differences were not statistically significant ( $p=0.15$, Table 2). In addition, ipsilateral SampEn was found to increase during VS in both $\mathrm{DCl}$ and non-DCl patients but without reaching statistical significance $(p=0.2$ for $D C l$ group and $p=0.8$ for non-DCl group, respectively, Table 3). Finally, and similarly with tau, SampEn did not differ between cohorts during different times of measurements.

\section{Bivariate correlations}

A moderate negative correlation was found between $\Delta S W$ (SWs VS-pre VS) and $\Delta M \times a$ (Mxa VS -Mxa pre VS) with Pearson $r=-0.37, p=0.04$, whereas CBFV SWs were also negatively correlated with tau during VS but at the limit of statistical significance $(r=-0.35, p=0.05)$. Finally, for all patients during VS, no correlation was found between ipsilateral mean CBFV and magnitude of CBFV SWs $(r=0.12, p=0.6)$, whereas a positive correlation was found before VS for the $\mathrm{DCl}$ group $(r=0.7, p<0.001)$.

\section{Prediction of $\mathrm{DCl}$}

Patients who developed DCl during hospitalization exhibited increased ipsilateral pre VS CBFV SWs, which were found to predict development of $\mathrm{DCl}$, as is depicted in Table 4. Thus, using the univariate results for variable selection, we found that one-unit change in pre VS SWs resulted in a 0.92-unit change in the log of the odds. ROC curve analysis found an area under the curve of $0.745(p=0.02$, Figure 3$)$. 
Table 4. Binary logistic regression model for predicting DCl.

\begin{tabular}{|lllcccc|}
\hline Parameter & B & SE & Wald & p value & OR & $95 \%$ Cl for OR \\
\hline Pre VS CBFV SWs & 0.92 & 0.44 & 4.33 & 0.03 & 2.52 & $1.05-6.02$ \\
\hline
\end{tabular}

VS: vasospasm, DCl: delayed cerebral ischemia, CBFV SWs: cerebral blood flow velocity slow waves, SE: standard error, $\mathrm{Cl}$ : confidence intervals, OR: odds ratio.

\section{Discussion}

In the present study, we measured and compared different TCD-derived hemodynamic and complexity indices of cerebrovascular dynamics, in order to investigate their behavior during VS in patients after $\mathrm{SAH}$, dichotomized by the presence of $\mathrm{DCl}$.

For the whole group of patients, we observed that during VS, CBFV SWs were found to increase in relation to the pre VS measurements (paired temporal comparisons). Similar differences were found between ipsilateral vs contralateral side during VS (paired spatial comparisons). Moreover, our findings confirm that VS can cause a disturbance of autoregulation at the side of aneurysm [3-5]. We also confirm previous study by Kasprowicz and colleagues [18], who found that tau is significantly reduced during VS even before formal TCD signs of VS are observed, suggesting a potentially therapeutic window for escalation of treatment.

CBFV SWs with an associated frequency range of 0.005 to $0.05 \mathrm{~Hz}$, reflect dynamic oscillations in cerebral blood volume related to autoregulatory vasodilatation and vasoconstriction [15]. Fluctuations of CBFV measured with TCD have been found to occur simultaneously with intracranial pressure (ICP) Bwaves and occupy the same frequency $[15,19$.

The physiological and clinical significance of SWs remains debated since they do not only occur during pathologic conditions but have also been observed in healthy subjects [15]. Thus, $\mathrm{pCO}_{2}$ changes related oscillations in the cerebrovascular volume, was believed to be one major mechanism of origin [28]. However, such theory does not seem to be universally advocated, since SWs have been also found in deeply sedated patients with stable $\mathrm{pCO}_{2}$ levels under mechanical ventilation [29].

According to Rosner [30], SWs are related to plateau waves of ICP waveforms, since they are generated by the same mechanism. Thus, an unstable ABP or faster and greater ABP decrements, induce vasodilatation when autoregulation is intact. Subsequently and through a vasodilatory cascade, the increase in cerebral blood volume and ICP promotes through a Cushing response an increase in ABP, terminating the pressure waves.

Others have suggested that SWs are derived from rhythmic cerebral vasoconstriction caused by an intrinsic brain stem rhythm, since their occurrence is independent from changes in $\mathrm{pCO}_{2}$ levels, $\mathrm{ABP}$ and 
respiration [31]. In this respect, general anesthesia has been found to reduce amplitude of SWs of ICP [32].

Greitz and colleagues [33], have proposed a different mechanism of origin of SWs. They suggested that restricted arterial distensibility due to decreased intracranial compliance in cases of chronic hydrocephalus, is associated with increased capillary pulsations and subsequently, increased CBFV SWs.

Stefanovska and coworkers [34], analyzing fluctuations in human peripheral blood flow, recognized 5 distinct oscillations, with frequency intervals between $0.02-0.05 \mathrm{~Hz}$ reflecting smooth muscle autonomic innervation, where frequencies lower than $0.05 \mathrm{~Hz}$ were related to both local neurogenic and metabolic inputs. Particularly, endothelial activity reflected in the concentration of different molecules secreted from endothelial cells, with vasodilatory or vasoconstrictive properties, such as nitric oxide (NO) and endothelin respectively, contributed to oscillations of around $0.01 \mathrm{~Hz}$. According to classic studies of Fry and Byrom [35.36], when cerebral arteries are narrowed, like in cases of VS, flow pulsations and wall shear stress will be enhanced, tending to increase the power dissipation and thus, the pressure gradient along the vascular tree. In this case, all sequential branches of the capillary network try to dilate in order to avoid or decrease this augmented pressure drop, through production of local vasodilatory molecules, such as NO. Such metabolic effects might be reflected in the amplitude of blood flow oscillations within a frequency range below $0.02 \mathrm{~Hz}$.

Based on the previous discussion, we suggest that increased CBFV SWs during VS in both temporal and spatial assessments that was found in our study, correspond to increased capillary stress. In this case, stiffening of large conduit arteries due to VS might induce increased and faster pressure and volume transmission into the brain capillaries. Although VS is mainly associated with vessel narrowing, where volume transmission is not necessarily increased, we suppose that shortened tau might reflect acceleration of the volume transmission, which in association with increased flow rate might enhance wall shear stress in the capillary network distal to insonation site. In this respect, a negative correlation between tau and SWs during VS was found but at the limit of statistical significance. Consequently, and according to Stefanovska's findings, such effects could increase amplitude of oscillations below $0.02 \mathrm{~Hz}$ due to enhanced production of different vasodilatory molecules, as an endothelial response to augmented shear stress. In addition, lack of significant correlation between ipsilateral mean CBFV and SWs might reflect their dissociation due to vessel lumen narrowing during VS, whereas ABP SWs did not differ significantly from pre VS values. Such findings further support our suggestion that increased magnitude of SWs during VS is mainly attributed to local mechanisms related to capillary stress. Finally, triple $\mathrm{H}$ therapy cannot account for our results, since ABP values did not differ significantly between pre VS and VS period of measurements.

Another finding of this study was the negative correlation between $\Delta S W$ and $\Delta M x$ a during VS. In this case, disturbed autoregulation during VS (even if it did not reach statistical significance) seems to be associated with modest increase in SWs. It seems that a highly decreased vasomotor tone or even vasoparalysis due to dysautoregulation, reflected in increased Mxa values, is associated with loss of 
pressure reactivity of cerebral blood vessels, limiting the ability of endothelial factors to induce oscillations in vessels' wall, with subsequent reduced amplitude of low frequency oscillations. Nevertheless, and since a significant stiffening of the arterial bed is also needed to explain our results, we assume that shortening of tau during VS partially reflects a decreased vascular compliance, as has already been suggested by Kasprowicz and colleagues [18].

Cerebral circulation can be considered as a complex system, since it involves both central and peripheral control mechanisms through multiple feedback loops [37]. Loss of complexity during illness might be attributed to altered coupling between system's components [38]. Decreased complexity reflects either decreased information content or decreased disorder, related to the number of 'microstates' that are accessible to the system [37].

Soehle and colleagues [16], evaluated variability and complexity of TCD-derived CBFV signals in patients suffering from SAH and found significantly reduced variability and complexity during VS, which was associated with unfavorable outcome. In addition, Placek and coworkers [17], using an index based on Renyi entropy, found that VS was associated with gradually increasing complexity of CBFV, attributed to a potential improvement in autoregulation and the number of regulatory mechanisms involved with its variability. In addition, complexity of blood flow was significantly reduced ipsilateral to aneurysm rupture related to contralateral side before occurrence of VS, suggesting, as in the case of tau, a potential therapeutic window.

In our investigation and similarly with Placek's study [17], SampEn was also reduced ipsilateral compared to contralateral side, both before and during VS, but without reaching statistical significance.

Furthermore, ipsilateral SampEn during VS was non significantly increased in relation to pre VS measurements. We suggest that differences between methods for assessing complexity could be responsible for inconsistency across different studies.

Cerebral autoregulation estimated with Mxa was found to be significantly impaired during VS in patients who developed DCl related to pre VS measurements. Moreover, ipsilateral Mxa values during VS were significantly increased in $\mathrm{DCl}$ compared to non-DCl groups (temporal comparisons). Finally, patients with $\mathrm{DCl}$ exhibited a significant interhemispheric difference in autoregulation, since Mxa during VS was found to increase in the ipsilateral related to contralateral side of aneurysm rupture (spatial comparisons). Such findings are in keeping with previous studies [4,5], which showed that development of $\mathrm{DCl}$ was associated with a significant interhemispheric difference of autoregulation in the first 5 days after ictus.

Measurement of ABP rather than CPP for calculation of Mx might limit accuracy of our results. However, both $\mathrm{Mx}$ and $\mathrm{Mxa}$ have been shown to exhibit good correlation, particularly in cases of impaired autoregulation in TBI patients, although Mxa was not found to differ between patients with different outcome [39]. In this respect, our findings agree with those of Calviere and coworkers [3], who showed that the combination of both large artery VS and impaired autoregulation estimated with Mxa during the first 7 days from ictus, was correlated to subsequent DCl. Another potential confounder in our study 
might be the arterial tension of $\mathrm{pCO}_{2}$, limiting accuracy of comparisons between patients [40].

Nevertheless, none from our patients had a history of chronic obstructive pulmonary disease or any other pulmonary disease that might affect $\mathrm{pCO}_{2}$ levels, assuming that its potential impact upon our

measurements might be insignificant. In any case, our results agree with those from other studies where no arterial tension $\mathrm{pCO}_{2}$ measurements were performed [3-5].

Ipsilateral CBFV SWs before VS were significantly increased in the DCl compared to the non-DCl cohort, whereas high $\triangle S W$ during VS was present only in patients who did not develop $\mathrm{DCl}$. Since there are no similar studies in the literature, we can only guess about the potential pathophysiological mechanisms of such findings. Thus, we suggest that patients with $\mathrm{DCl}$ might experience an increased capillary stress even before the occurrence of VS; however, lack of differences between groups in terms of pre-VS values of Mxa or tau might signal different mechanisms of origin. Perhaps the increased heterogeneity of flow during the first days after SAH, which has been found in studies using direct perfusion methodology [41], suggest focal impairment of autoregulation that cannot be captured with TCD-derived indices. In this respect, a positive correlation was found between mean CBFV and SWs before VS in the DCl group, reflecting an association between SWs and fluctuations in CBF.

Furthermore, increased pre VS SWs could also be attributed to enhanced local neurogenic inputs originating in the brain stem, which are independent of the sympathetic nervous system [42]. Probably, in cases of highly focal disturbances of flow and autoregulation, inputs from the brain stem towards cerebral blood vessels are increased, in order to preserve CBF at the level of microcirculation. In such cases, magnitude of CBFV SWs will be augmented, since different local neurogenic mechanisms are also considered responsible for blood flow oscillations within a frequency range below $0.02 \mathrm{~Hz}$ [34]. In this respect, no differences were found between ABP SWs before and during VS, either between or within groups. Finally, ABP mean values were not different between groups. Thus, the association of high pre VS SWs with occurrence of $\mathrm{DCl}$ might reflect the significant predictive value of regional dysautoregulation. Nevertheless, these results need to be validated in a larger prospective study.

Finally, attenuated increase in CBFV SWs during VS in DCl patients related to non-DCl group, could be related to a state of vasoparalysis, since such condition may partially account for a reduction in blood vessels oscillatory capacity. Moreover, microvascular endothelial dysfunction and spasm could also be associated with lack of change in SWs during VS. Thus, experimental studies have found that cortical arterioles after VS due to SAH demonstrate attenuated dilation to different endothelial-dependent dilators, such as NO and adenosine diphosphate [43].

Some of the major limitations of this study is its retrospective nature, as well as the small sample size that might account for some of the negative associations found. Nevertheless, we included only conscious patients, in order to increase homogeneity of studied population, as well as to have clinically proven diagnosis of $\mathrm{DCl}$, since its diagnosis in sedated subjects is more difficult and depends on different imaging techniques [23]. Moreover, the mixture of both sedated and conscious patients might dilute findings in terms of SWs changes [32]. In addition, mean CBFV did not differ between groups 
significantly, both before and during spasm. Thus, our patients seem to have similar severity of VS, limiting its potential impact on our findings. Our results are in keeping with those from other investigators who evaluated relationships between different TCD-derived cerebrovascular parameters with outcome, in similar patients' groups. Non-invasive ABP measurement for $\mathrm{Mx}$ calculation through Finapres system could constitute another limitation in terms of accuracy of results. However, agreement between invasive and non-invasive assessment of $\mathrm{Mx}$ has been tested and a good correlation between the two methods was found [44].

Since TCD has limited spatial resolution, it is conceivable that regional disturbance of autoregulation, particularly affecting the posterior circulation might have been missed. Moreover, TCD cannot detect microvascular spasm, a potential mechanism of modest $\triangle \mathrm{SW}$ increase during $\mathrm{VS}$ in $\mathrm{DCl}$ group.

In conclusion, we suggest that CBFV SWs even in the early days post ictus might help identify patients who are more susceptible to development of $\mathrm{DCl}$ throughout their hospital course. Moreover, simultaneous analysis of ICP and CBFV could enhance accuracy of measurements through estimation of CPP instead for $\mathrm{ABP}$, whereas parallel monitoring of arterial tension of $\mathrm{pCO}_{2}$ that affects thresholds of disturbed autoregulation might improve accuracy of comparisons between patients.

\section{Conclusions}

Slow waves of CBFV in $\mathrm{DCl}$ group were significantly higher before VS and predicted unfavorable outcome. Consequently, we suggest that following SAH, their daily monitoring through TCD measurements at the bedside, could improve understanding of complex physiology and eventually, optimize treatment.

\section{Abbreviations}

ABP: arterial blood pressure,

AMP: amplitude,

AUC: area under the curve,

CBF: cerebral blood flow,

CBFV: cerebral blood flow velocity,

Ca: compliance,

CPP: cerebral perfusion pressure,

CVR: cerebral vascular resistance,

DCl: delayed cerebral ischemia, 
GSC: Glasgow Coma Scale,

GOS: Glasgow Outcome scale,

ICA: internal carotid artery,

ICP: intracranial pressure,

LR: Lindegaard ratio,

MCA: middle cerebral artery,

Mxa: mean velocity autoregulatory index,

ROC: Receiver Operating Characteristic,

SAH: subarachnoid hemorrhage,

SampEn: sample entropy,

SWs: slow waves,

tau: time constant,

TCD: transcranial Doppler,

VS: vasospasm,

WFNS: World Federation of Neurosurgical Societies scale.

\section{Declarations}

\section{Ethics approval and consent to participate}

This is a retrospective analysis of previously prospectively gathered data. For this type of study formal consent is not required.

However, written consent and approval of the previous studies including the same patients was given by both patients and the local Addenbrooke's Research Ethics Committee, respectively.

\section{Consent for publication}

Not applicable

\section{Availability of data and materials}


The datasets used and analyzed during the current study are available from the corresponding author on reasonable request.

\section{Competing interests}

All authors except for MC and PS certify that they have no affiliations with or involvement in any organization or entity with any financial interest (such as honoraria; educational grants; participation in speakers' bureaus; membership, employment, consultancies, stock ownership, or other equity interest; and expert testimony or patent-licensing arrangements), or non-financial interest (such as personal or professional relationships, affiliations, knowledge or beliefs) in the subject matter or materials discussed in this manuscript.

$\mathrm{MC}$ and PS have financial interests in part of the licensing fees for the software ICM+ used in this project for data collection and analysis.

\section{Funding}

Not applicable

\section{Authors' contributions}

VP was the principal investigator who made the analyses and wrote the manuscript.

KB was the investigator who provided the data from previous prospective studies and edited the manuscript.

MP assisted to the software applications for data analysis and statistics.

ZC assisted to the software applications for data analysis and statistics and edited the manuscript.

PS assisted to the software applications for data analysis and statisticsand edited the manuscript.

MC assisted to the software applications for data analysis and statistics and edited the manuscript.

\section{Acknowledgments}

Not applicable

\section{References}

1. Budohoski K, Guilfoyle M, Helmy A, Huuskonen T, Czosnyka M, Kirollos R, Menon DK, Pickard JD, Kirkpatrick PJ (2014) The pathophysiology and treatment of delayed cerebral ischemia following subarachnoid hemorrhage. J Neurol Neurosurg Psychiatry 85: 1343-53.

2. Rowland MJ, Hadjipavlou G, Kelly M, Westbrook J, Pattinson KTS (2012) Delayed cerebral ischemia after subarachnoid hemorrhage: looking beyond vasospasm. BJA 109(3): 315-329. 
3. Calviere L, Nasr N, Arnaud C, Czosnyka M, Viguier A, Tissot B, Sol JC, Larrue V (2015) Prediction of delayed cerebral ischemia after subarachnoid hemorrhage using cerebral blood flow velocities and cerebral auto-regulation assessment. Neurocrit Care 32(2): 253-258.

4. Budohoski K, Czosnyka M, Kirkpatrick PJ, Reinhard M, Varsos GV, Kasprowicz M, Ząbek M, Pickard JD, Smielewski P (2015) Bilateral failure of cerebral autoregulation is related to unfavorable outcome after subarachnoid hemorrhage. Neurocrit Care 22(1): 65-73.

5. Budohoski K, Czosnyka M, Smielewski P, Kasprowicz M, Helmy A, Bulters D, Pickard JD, Kirkpatrick PJ (2012) Impairment of cerebral autoregulation predicts delayed cerebral ischemia after subarachnoid hemorrhage. Stroke 43(12): 3230-37.

6. Harper MA (1966) Autoregulation of cerebral blood flow: influence of the arterial blood pressure on the blood flow through the cerebral cortex. J Neurol Neurosurg Psyciatry 29: 398-403.

7. Budohoski K, Czosnyka M, Kirkpatrick P, Smielewski P, Steiner L, Pickard J (2013) Clinical relevance of cerebral autoregulation following subarachnoid hemorrhage. Nat Rev Neurol 9(3): 152-163.

8. Cahill J, Calvert JW, Zhang JH (2006) Mechanism of early brain injury after subarachnoid hemorrhage. J Cereb Blood Flow Metab 26: 1341-1353.

9. Aaslid R, Markwalder TM, Nornes H (1982) Noninvasive transcranial Doppler recordings of flow velocity in basal cerebral arteries. J Neurosurg 57: 769-774.

10. Czosnyka M, Smielewski P, Kirkpatrick P, Menon DK, Pickard JD (1996) Monitoring of cerebral autoregulation in head-injured patients. Stroke 27(10): 1829-1834.

11. Czosnyka M, Richards H, Pickard JD, Harris N, lyer V (1994) Frequency-dependent properties of cerebral blood transport-an experimental study in anaesthetized rabbits. Ultrasound Med Biol 20: 391-399.

12. Varsos GV, Kasprowicz M, Smielewski P, Czosnyka M (2014) Model-based indices describing cerebrovascular dynamics. Neurocrit Care 20(1): 142-157.

13. Kim DJ, Kasprowicz M, Carrera E, Castellani G, Zweifel C, Lavinio A, Smielewski P, Sutcliffe MP, Pickard JD, Czosnyka M (2009) The monitoring of relative changes in compartmental compliances of brain. Physiol Meas 30(7): 647-659.

14. Kasprowicz M, Diedler J, Reinhard M, Carrera E, Steiner LA, Smielewski P, Budohoski KP, Haubrich C, Pickard JD, Czosnyka M (2012) Time constant of the cerebral arterial bed in normal subjects. Ultrasound Med Biol 38(7): 1129-1137.

15. Spiegelberg A, Preuß M, Kurtcuoglu V (2016) B-waves revisited. Interdiscip Neurosurg 6:13-17.

16. Soehle M, Czosnyka M, Chatfield DA, Heft A, Pena A (2008) Variability and fractal analysis of middle cerebral artery blood flow and arterial blood pressure in subarachnoid hemorrhage. $\mathrm{J}$ Cereb Blood Flow Metab 28: 64-73.

17. Placek MM, Wachel P, Czosnyka M, Soehle M, Smielewski P, Kasprowicz M (2015) Complexity of cerebral blood flow velocity and arterial blood pressure in subarachnoid hemorrhage using timefrequency analysis. Conf Proc IEEE Eng Med Biol Soc 2015: 7700-7703. 
18. Kasprowicz M, Czosnyka M, Soehle M, Smielewski P, Kirkpatrick PJ, Pickard JD, Budohoski KP (2011) Vasospasm shortens cerebral arterial time constant. Neurocrit Care 16(2): 213-218.

19. Balestreri M, Czosnyka M, Steiner LA, Schmidt E, Smielewski P, Matta B, Pickard JD (2004) Intracranial hypertension: what additional information can be derived from ICP waveform after head injury? Acta Neurochir 146(2): 131-141.

20. Suarez JI, Qureshi Al, Yahia AB, Parekh PD, Tamargo RJ, Williams MA, Ulatowski JA, Hanley DF, Razumovsky AY (2002) Symptomatic vasospasm diagnosis after subarachnoid hemorrhage: evaluation of transcranial Doppler ultrasound and cerebral angiography as related to compromised vascular distribution. Crit Care Med 30: 1348-1355.

21. Lindegaard KF, Nornes H, Bakke SJ, Sorteberg W, Nakstad P (1989) Cerebral vasospasm diagnosis by means of angiography and blood velocity measurements. Acta Neurochir (Wien) 100: 12-24.

22. Vergouwen MD, Vermeulen M, van Gijn J, Rinkel GJ, Wijdicks EF, Muizelaar JP, Mendelow AD, Juvela S, Yonas H, Terbrugge KG, Macdonald RL, Diringer MN, Broderick JP, Dreier JP, Roos YB (2010) Definition of delayed cerebral ischemia after aneurysmal subarachnoid hemorrhage as an outcome event in clinical trials and observational studies: proposal of a multidisciplinary research group. Stroke 41(10): 2391-2395.

23. Connolly ES, Rabinstein AA, Carhuapoma JR, Derdeyn CP, Dion J, Higashida RT, Hoh BL, Kirkness CJ, Naidech AM, Ogilvy CS, Patel AB, Thompson BG, Vespa P (2012) Guidelines for the management of aneurysmal subarachnoid hemorrhage: a guideline for health care professionals from the American Heart Association/ American Stroke Association. Stroke 43(6): 1711-1737.

24. Claassen J, Bernardini GL, Kreiter K, Bates J, Du YE, Copeland D, Connolly ES, Mayer SA (2001) Effect of cisternal and ventricular blood on risk of delayed cerebral ischemia after subarachnoid hemorrhage: the Fisher scale revisited. Stroke 32(9): 2012-2020.

25. Avezaat CJJ, van Eijndhoven JHM (1984) Cerebrospinal fluid pulse pressure and craniospinal dynamics. A theoretical and experimental study. Dissertation, University of Amsterdam.

26. Soehle M, Czosnyka M, Pickard JD, Kirkpatrick PJ (2004) Continuous assessment of cerebral autoregulation in subarachnoid hemorrhage. Anesth Analg 98: 1133-1139.

27. Richmann JS, Moorman JR (2000) Physiological time-series analysis using approximate entropy and sample entropy. Am J Physiol Heart Circ Physiol 278: 2039-2049.

28. Lundberg $N$ (1959) Continuous recording and control of ventricular fluid pressure in neurosurgical practice. Acta Pychiatr Scand Suppl 36(149): 1-193.

29. Czosnyka M (2004) Monitoring and interpretation of intracranial pressure. J Neurol Neurosurg Psychiatry 75(6): 813-821.

30. Rosner MJ (1986) The vasodilatory cascade and intracranial pressure. In: Miller JD, Teasdale GM, Rowan JO, Galbraith SL, Mendelow AD (eds) Intracranial pressure VI, Springer, Heidelberg, pp 137141.

31. Lescot T, Naccache L, Bonnet MP, Abdennour L, Coriat P, Puybasset L (2005) The relationship of intracranial pressure Lundberg waves to electroencephalograph fluctuations in patients with severe 
head trauma. Acta Neurochirurgica 147(2): 125-129.

32. Lalou DA, Czosnyka M, Donnelly J, Lavinio A, Pickard JD, Garnett M, Czosnyka Z (2016) Influence of general anaesthesia on slow waves of intracranial pressure. Neurol Res 38(7): 587-592.

33. Greitz D (2004) Radiological assessment of hydrocephalus: new theories and implications for therapy. Neurosurg Rev 27(3): 145-165.

34. Stefanovska A, Bracic M, Kvernmo HD (1999) Wavelet analysis of oscillations in the peripheral blood circulation measure by laser Doppler flowmetry. IEEE Trans Biomed Eng 46(10): 1230-1239.

35. Fry DL (1968) Acute vascular endothelial changes associated with increased blood velocity gradients. Circ Res 22: 165-197.

36. Byrom FB, Dodson LF (1949) The mechanism of the vicious cycle in chronic hypertension. Clin Sci 8: 1-10.

37. Goldberger AL, Peng CK, Lipsitz LA (2002) What is physiologic complexity and how does it change with aging and disease? Neurobiol Aging 23(1): 23-26.

38. Godin PJ, Buchman TG (1996) Uncoupling of biological oscillators: a complementary hypothesis concerning the pathogenesis of multiple organ dysfunction syndrome. Crit Care Med 24(7): 11071116.

39. Lewis PM, Smielewski P, Pickard JD, Czosnyka M (2007) Dynamic cerebral autoregulation: should intracranial pressure be taken into account? Acta Neuroschir (Wien) 149(6): 549-555.

40. Czosnyka M, Brady K, Reinhard M, Smielewski P, Steiner LA (2009) Monitoring of cerebral autoregulation: Fcts, myths, amd missing links. Neurocrit Care 10: 373-386.

41. Mustonen T, Koivisto T, Vanninen E, Vanninen R, Kuikka JT (2006) Cerebral perfusion heterogeneity and complexity in patients with acute subarachnoid hemorrhage. Nucl Med Commun 27(2): 157-164.

42. Scatton B, Duverger D, L'Heureux R, Serrano A, Fage D, Nowicki JP, MacKenzie ET (1985) Neurochemical studies on the existence, origin and characteristics of the serotonergic innervation of small pial vessels. Brain Res 345(2): 219-229.

43. Park KW, Metais C, Dai HB, Comunale ME, Sellke FW (2001) Microvascular endothelial disruption and its mechanism in a rat model of subarachnoid hemorrhage. Anesth Analg 92: 990-996.

44. Lavinio A, Schmidt EA, Haubrich C, Smielewski P, Pickard JD, Czosnyka M (2007) Noninvasive evaluation of dynamic cerebrovascular autoregulation using Finapres plethysmograph and transcranial Doppler. Stroke 38(2): 402-404.

\section{Figures}




\section{Figure 1}

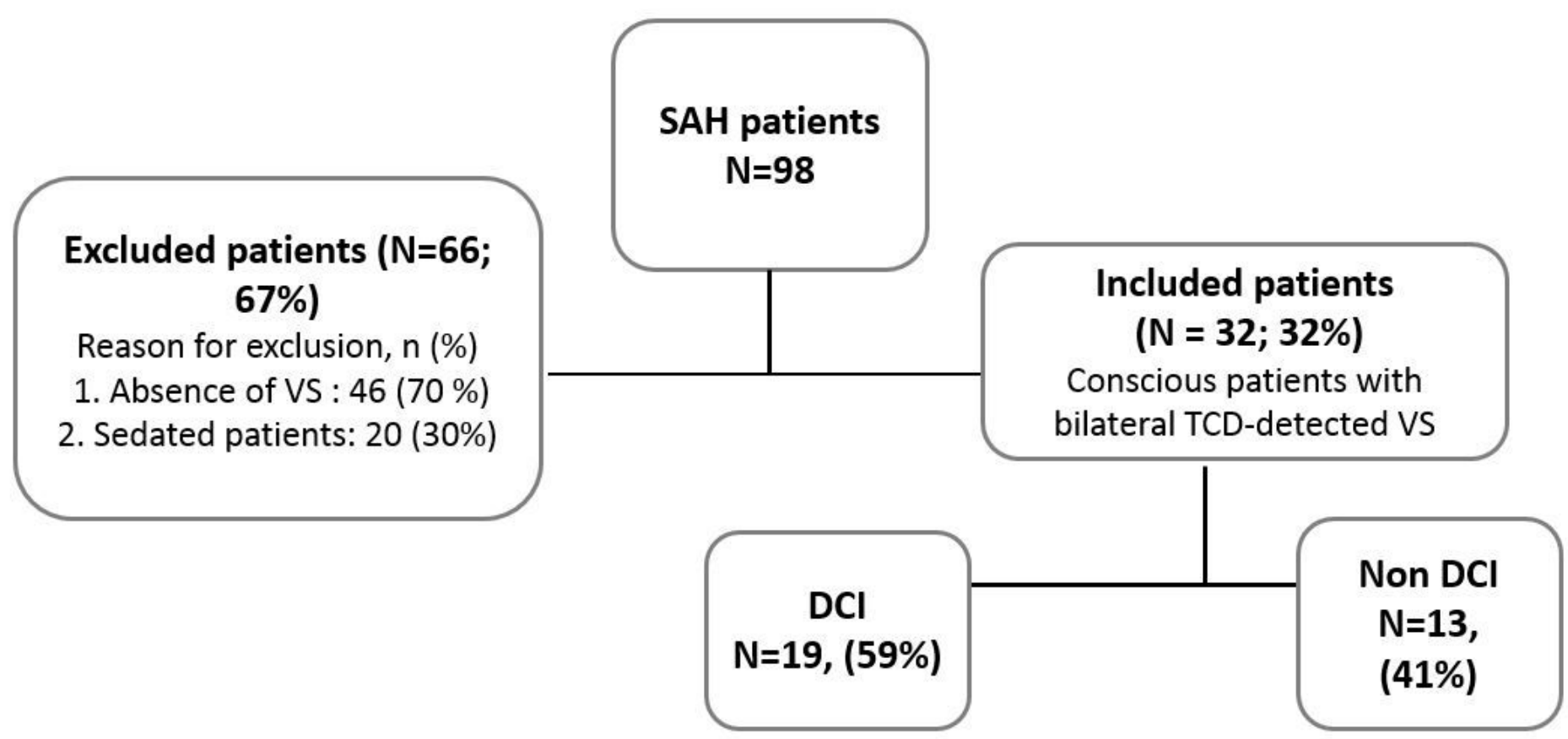

Figure 1

Flow chart of the study. From a data base of 98 patients with SAH, 46 patients (70\%) did not develop TCD-detected VS. Furthermore, from the remaining 52 cases with VS, 20 sedated patients were excluded from the study $(30 \%)$. Included conscious subjects $(\mathrm{N}=32)$ were subsequently dichotomized in 19 patients who developed $\mathrm{DCl}$ vs 13 without $\mathrm{DCl}$, within 21 of ictus. 


\section{Figure 1}

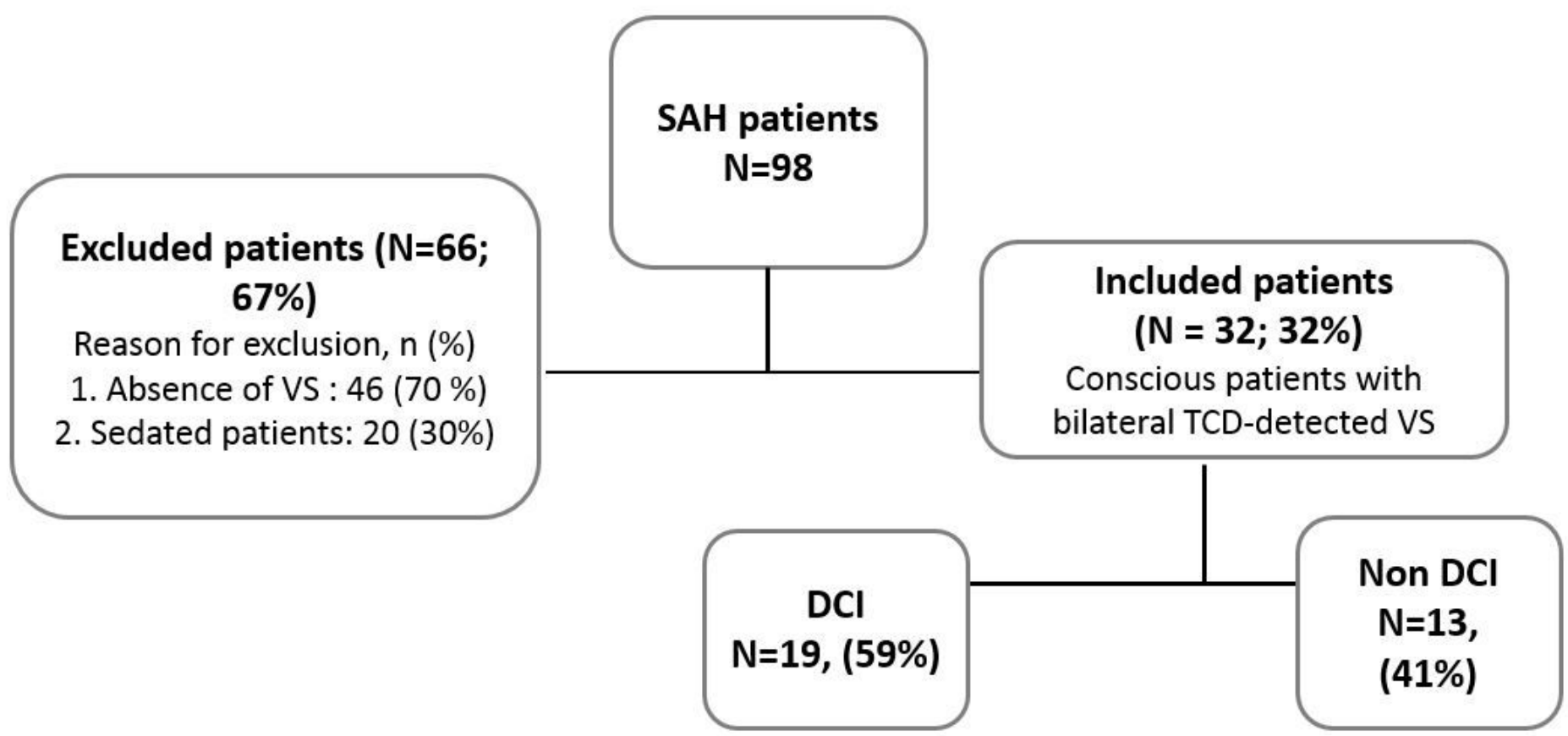

\section{Figure 1}

Flow chart of the study. From a data base of 98 patients with SAH, 46 patients (70\%) did not develop TCD-detected VS. Furthermore, from the remaining 52 cases with VS, 20 sedated patients were excluded from the study (30\%). Included conscious subjects ( $N=32$ ) were subsequently dichotomized in 19 patients who developed DCl vs 13 without DCl, within 21 of ictus. 
Figure 2

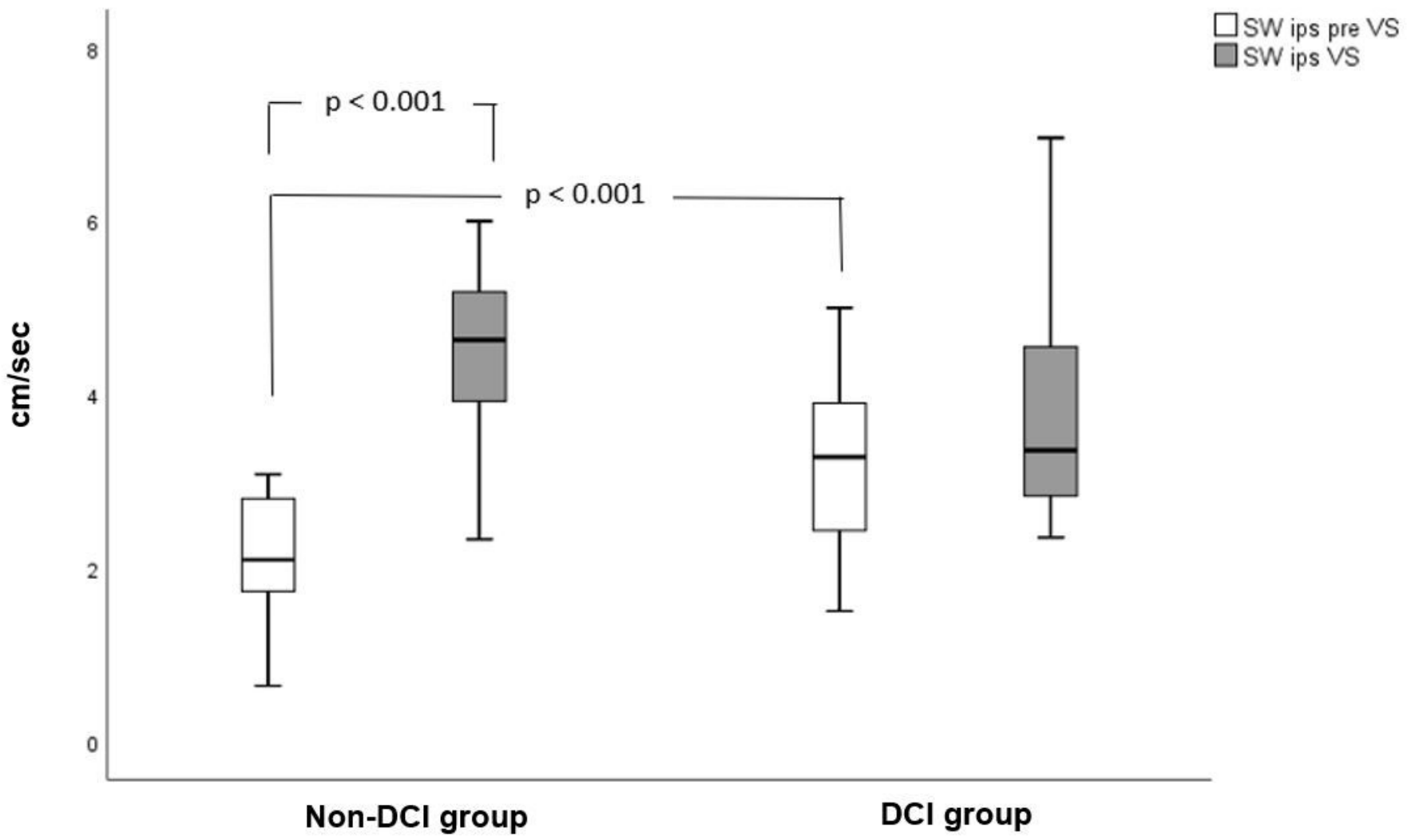

Figure 2

Statistically significant differences of ipsilateral CBFV SWs before vasospasm (pre VS) are illustrated between delayed cerebral ischemia (DCl) and non-DCl groups, as well as between pre VS and during VS measurements within non-DCl group. Units of measurement in the $y$ axis are $\mathrm{cm} / \mathrm{sec}$. 
Figure 2

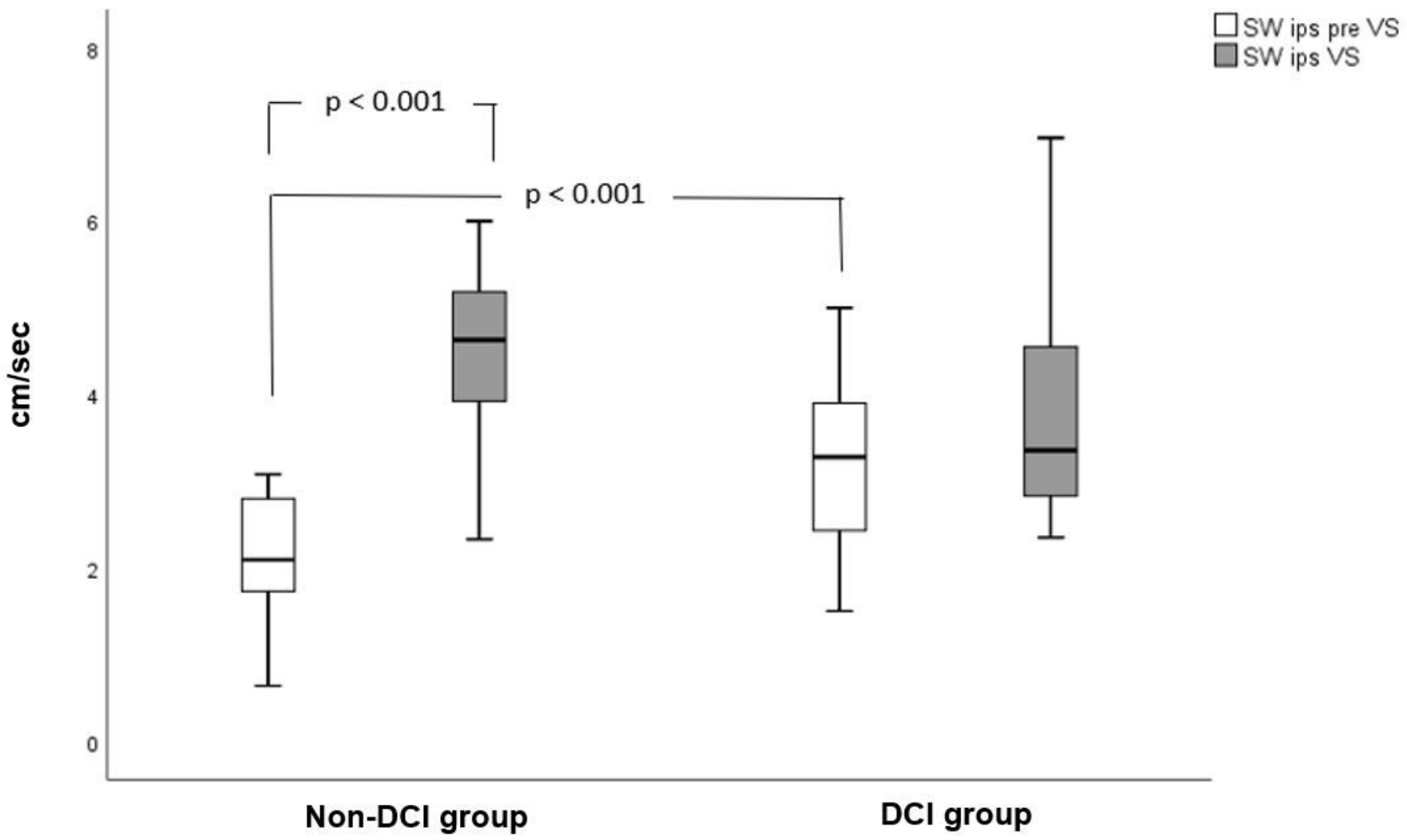

Figure 2

Statistically significant differences of ipsilateral CBFV SWs before vasospasm (pre VS) are illustrated between delayed cerebral ischemia (DCl) and non-DCl groups, as well as between pre VS and during VS measurements within non-DCl group. Units of measurement in the $y$ axis are $\mathrm{cm} / \mathrm{sec}$. 


\section{Figure 3}

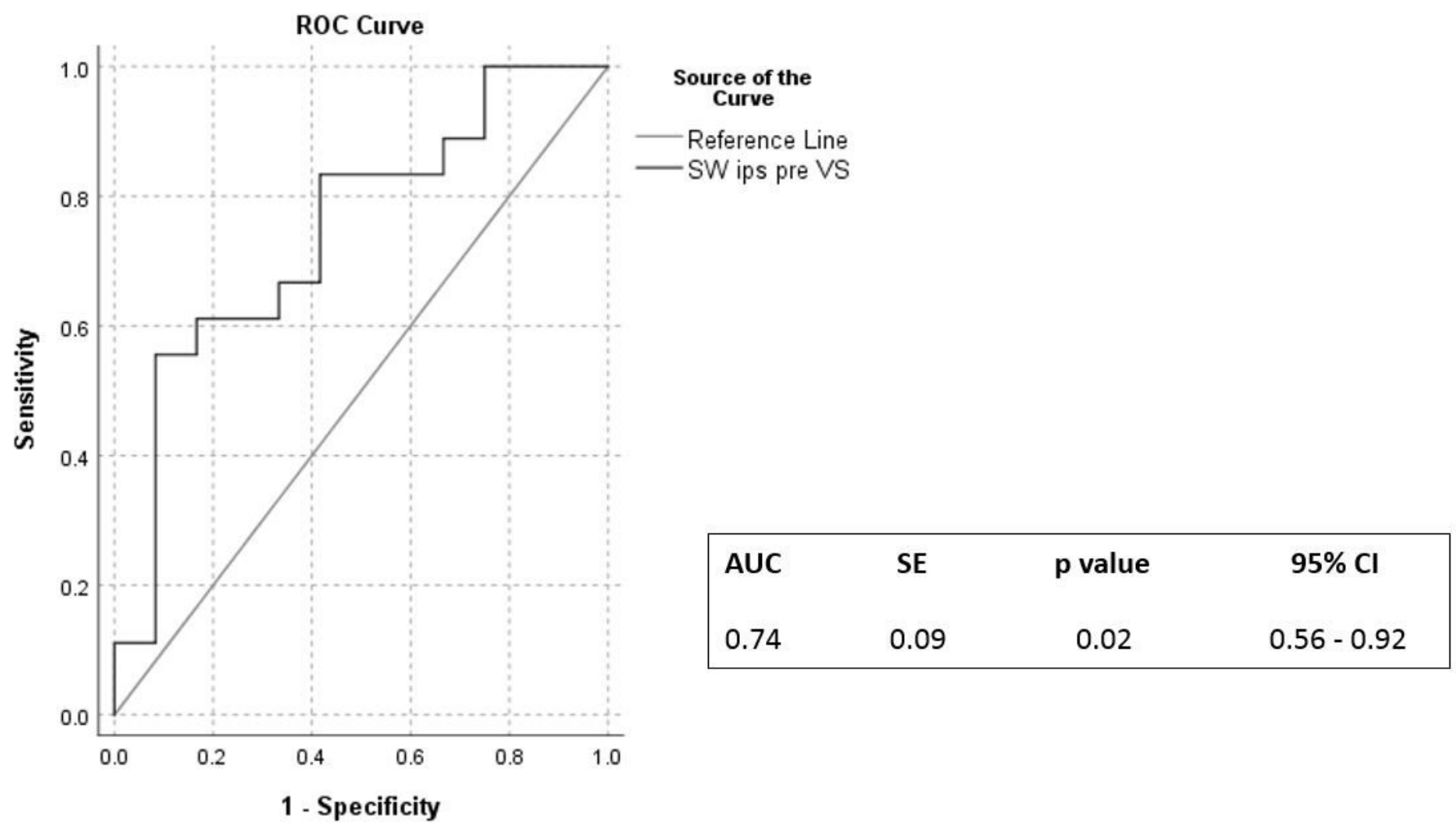

\section{Figure 3}

Receiver Operating Characteristic (ROC) curve with p values, standard error (SE) and 95\% confidence intervals (Cl) of the area under the curve (AUC) of ipsilateral cerebral blood flow velocity slow waves before vasospasm (SW ips pre VS), for predicting delayed cerebral ischemia. 


\section{Figure 3}

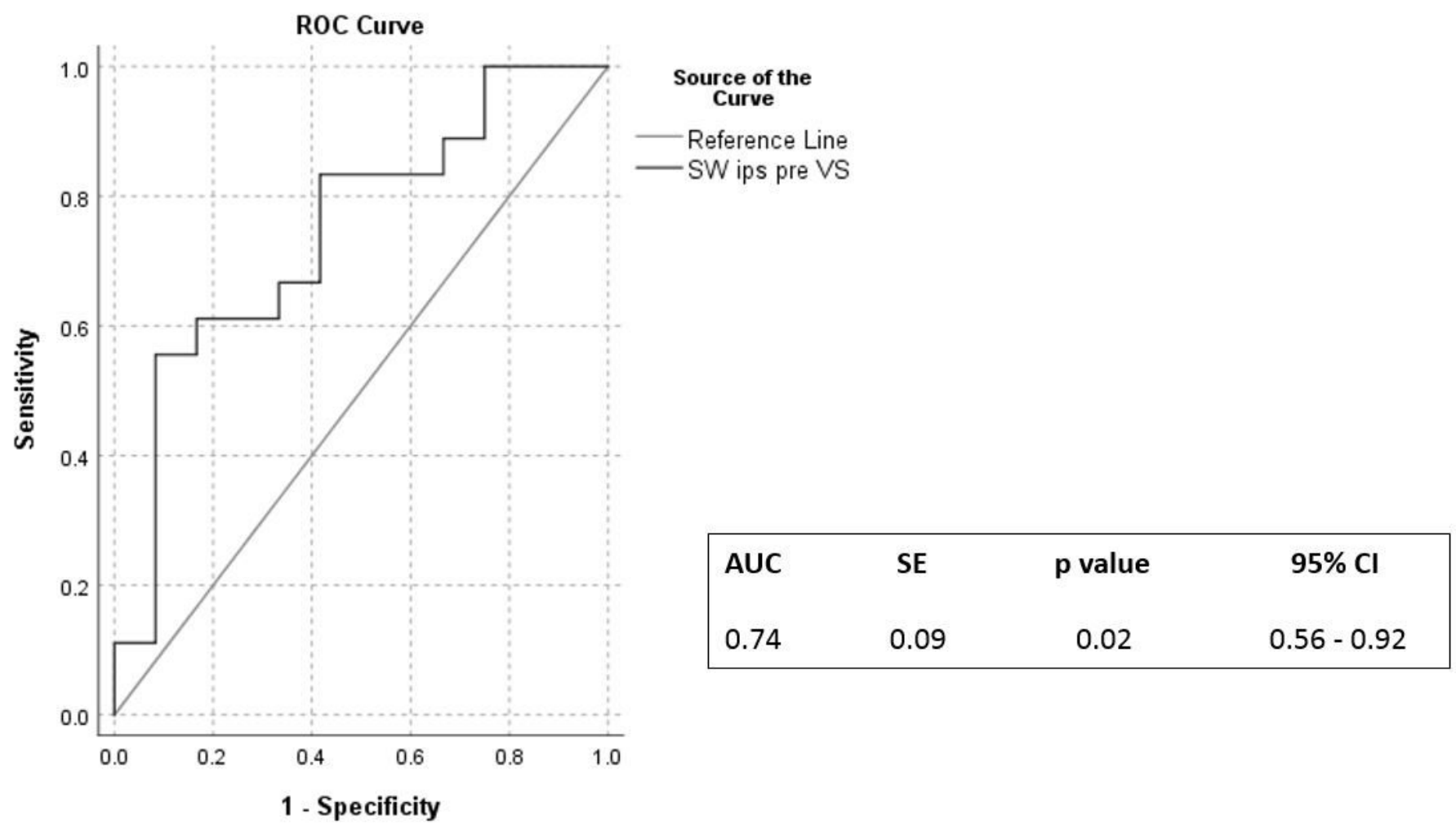

\section{Figure 3}

Receiver Operating Characteristic (ROC) curve with p values, standard error (SE) and 95\% confidence intervals (Cl) of the area under the curve (AUC) of ipsilateral cerebral blood flow velocity slow waves before vasospasm (SW ips pre VS), for predicting delayed cerebral ischemia. 